\title{
Numerical Analysis of the Energy Improvement of Plastering Mortars with Phase Change Materials
}

\author{
A. Váz Sá, ${ }^{1}$ R. M. S. F. Almeida, ${ }^{2,3}$ H. Sousa, ${ }^{1}$ and J. M. P. Q. Delgado ${ }^{3}$ \\ ${ }^{1}$ Construction Technology, Quality and Management (GEQUALTEC), Faculdade de Engenharia da Universidade do Porto, \\ Rua Dr. Roberto Frias s/n, 4200-465 Porto, Portugal \\ ${ }^{2}$ Polytechnic Institute of Viseu-School of Technology \& Management, Campus Politécnico de Repeses, \\ 3504-510 Viseu, Portugal \\ ${ }^{3}$ Laboratory of Building Physics (LFC), Civil Engineering Department, Faculdade de Engenharia da Universidade do Porto, \\ Rua Dr. Roberto Frias s/n, 4200-465 Porto, Portugal
}

Correspondence should be addressed to J. M. P. Q. Delgado; jdelgado@fe.up.pt

Received 28 February 2014; Accepted 13 March 2014; Published 10 April 2014

Academic Editor: A. G. Barbosa de Lima

Copyright (C) 2014 A. Váz Sá et al. This is an open access article distributed under the Creative Commons Attribution License, which permits unrestricted use, distribution, and reproduction in any medium, provided the original work is properly cited.

Building components with incorporated phase change materials (PCMs) meant to increase heat storage capacity and enable stabilization of interior buildings surface temperatures, whereby influencing the thermal comfort sensation and the stabilization of the interior ambient temperatures. The potential of advanced simulation tools to evaluate and optimize the usage of PCM in the control of indoor temperature, allowing for an improvement in the comfort conditions and/or in the cooling energy demand, was explored. This paper presents a numerical and sensitivity analysis of the enthalpy and melting temperature effect on the inside building comfort sensation potential of the plastering PCM.

\section{Introduction}

Nanotechnology and nanoproducts offer interesting new opportunities in many civil engineering areas and architecture including design and construction processes, such as the development of novel insulation materials. These novel materials with very good insulation values are already available on the market, enable a thermal rehabilitation of buildings in which conventional insulation is not possible, and can help to improve energy efficiency. On the construction industry not all products that feature the term "nano" actually contain nanomaterials. Often, the term "nano" merely refers to structures in the nanosize range. Nanotechnology in the construction industry is currently concentrated in the following sectors:

(i) cement-bound construction materials,

(ii) noise reduction and thermal insulation or temperature regulation, (iii) surface coatings to improve the functionality of various materials,

(iv) fire protection.

This paper presents the application of nanotechnology, in the construction process, to improve the building energy efficiency. One of the greatest challenges in the construction sector is the thermal renovation of existing buildings; and applying new insulation materials based on nanotechnology could make an important contribution. In the past, energy consumption has increased steadily. However, the energy efficiency of buildings is today a prime objective for energy policy at regional, national, and international levels [1]. Innovations attributable to nanotechnology also enable thermally insulating buildings in which a conventional insulation is not possible (e.g., in older buildings with structured facade) and thereby achieve very good insulation values, for example, aerogels, phase change materials (PCMs), and vacuum insulation panels. 
A PCM is a substance that changes from one state of matter to another at a certain temperature and represents a technology that may reduce peak loads and HVAC energy consumption in buildings. Building materials with incorporated PCM are meant to increase heat storage capacity and enable stabilization of building interior surface temperature, whereby influencing the thermal comfort sensation and the stabilization of the interior ambient temperatures [2].

Thermal energy storage based on the latent heat of phase change material has attracted attention of researchers and engineers in different fields, and a considerable number of numerical researches on PCMs have attempted to estimate potential energy savings through building energy simulation. To analyse energy and peak load benefits from PCMs a significant number of commercial building energy simulation programs such as CoDyBa, EnergyPlus, ESP-r, and TRNSYS were used.

EnergyPlus PCM algorithm uses a one-dimensional conduction finite difference solution algorithm (CondFD). This algorithm was tested and validated against multiple tests suites [3, 4]. However, when simulating complex models over extended periods this procedure becomes very time consuming and computationally demanding. In the problem under study the objective is to evaluate and minimize the annual heating load while guaranteeing a good thermal comfort performance.

As far as the organization of this paper is concerned, Sections 2 and 3 deal with the manufacturing methods used for the achievement of the PCM-based plastering mortar, as well as with the characterization of the developed material. Section 4 is dedicated to the numerical analysis of the plastering mortars energy improvement with phase change materials, with the BESTest (Building Energy Simulation Test) of EnergyPlus. Section 5 closes the paper with the main conclusions and prospects of the research work.

\section{Phase Change Materials (PCMs)}

2.1. Properties, Groups, and Categories. Thermal comfort of interior building spaces can be achieved using sensible heat form, related to conventional building materials, or via latent heat form, associated with PCMs. PCMs used for latent heat storage in buildings are characterized by an endothermic behaviour (with energy accumulation) during solid-liquid transition and exothermal process (with energy liberation) during liquid-solid phase shift. The solid-liquid PCM group comprises three categories: organic PCMs (paraffins and fatty acids); inorganic PCMs (salt hydrates and metallics); and eutectic mixtures (organic-organic, organic-inorganic, and inorganic-inorganic).

Thermal properties, like melting temperature and phase change enthalpy, are crucial to the process of selecting a suitable PCM for thermal energy storage. The scheme shown in Figure 1 makes a distribution of the existing PCMs trough those two essential thermal properties.

Salt hydrates and eutectic mixtures present the highest phase change enthalpy for the operative temperatures required inside building spaces. However, the set of characteristics presented by paraffins makes of these the most

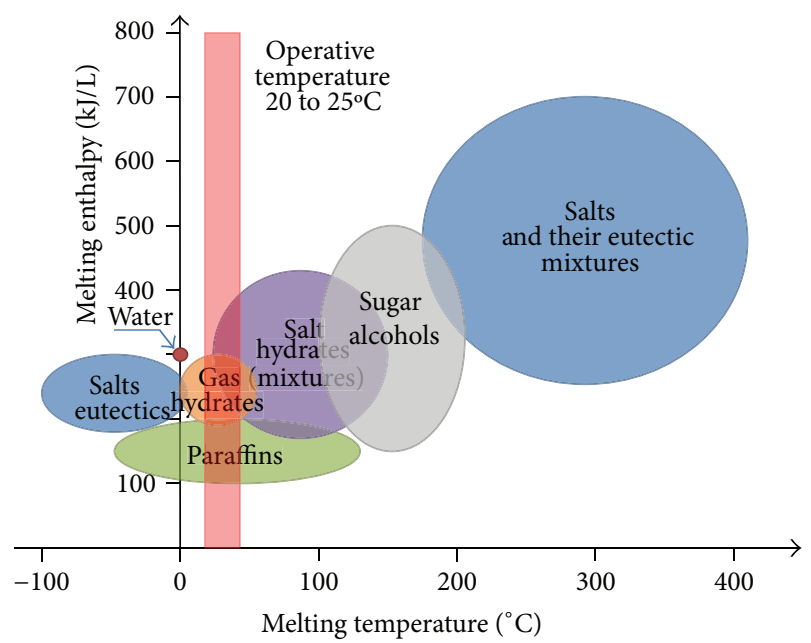

FIGURE 1: Melting temperatures and phase change enthalpy for existing PCMs (adapted from [7]).

desirable materials to be used in latent heat storage systems. Organic materials, such as paraffins, are chemically stable, offer no supercooling, and are available in a large temperature range with low cost.

2.2. PCM in Building Materials: Incorporation Methods. Phase change materials can be incorporated into conventional construction materials mainly by three different technics: direct incorporation, immersion, and encapsulation [8]. Direct incorporation is the simplest method in which liquid or powdered PCMs are directly added to building materials such as gypsum, concrete, or plaster during production. Immersion technic of PCM is used in porous construction materials such as concrete or bricks. Those materials are dipped into melted PCM that is absorbed by capillarity. With direct incorporation or immersion methods construction materials are imposed to be in contact with PCM. No extra equipment is needed in both methods but leakage and incompatibility with construction materials may be the biggest problems [9].

To avoid incompatibility problems, due to the direct contact between conventional construction materials and PCMs, encapsulation method arises. Encapsulation eases the process of handling and incorporating of PCM into building materials, the leakage problem can be avoided, and the function of the construction structure can be less affected.

Macroencapsulation for PCM can present many different shapes, tubes, spheres, or panels, and can be obtained from several materials like aluminium or polymers. Macroencapsulated PCMs can be easily placed in ceilings [10] or underfloor systems [11]. It has the disadvantages of poor thermal conductivity and tendency of solidification at the edges (crystallization) [12]. Microencapsulation can be described as the technology in which PCM particles are enclosed in a thin, sealed, and high molecular weight polymeric film. Microcapsules, with diameters that can vary from 1 to $1000 \mu \mathrm{m}$, prevent PCM from leakage during the phase change process. Microencapsulated PCMs are easy to incorporate and do 
TABLE 1: Required tests for hardened mortars of general purpose (GP) and of lightweight (LW).

\begin{tabular}{|c|c|c|c|}
\hline \multirow{2}{*}{ Test parameter } & \multirow{2}{*}{ Test methods } & \multicolumn{2}{|c|}{ Requirements } \\
\hline & & GP & LW \\
\hline Dry bulk density $\left[\mathrm{kg} / \mathrm{m}^{3}\right]$ & EN 1015-10 & Declared range of values & $\begin{array}{l}\text { Declared range of values: } \\
\qquad \rho \leq 1300 \mathrm{~kg} / \mathrm{m}^{3}\end{array}$ \\
\hline Compressive strength $\left[\mathrm{N} / \mathrm{mm}^{2}\right]$ & EN 1015-11 & CS I to CS IV & CS I to CS III \\
\hline Adhesion $\left[\mathrm{N} / \mathrm{mm}^{2}\right]$ and fracture pattern $\mathrm{FP}(\mathrm{A}, \mathrm{B}$, or $\mathrm{C})$ & EN 1015-12 & \multicolumn{2}{|c|}{$\geq$ declared value and FP } \\
\hline Capillary water absorption & EN 1015-18 & \multicolumn{2}{|c|}{ W0 to W2 } \\
\hline Water vapour permeability coefficient $(\mu)$ & EN 1015-19 a b & \multicolumn{2}{|c|}{$\leq$ declared value } \\
\hline Thermal conductivity $\left[\mathrm{W} /\left(\mathrm{m} \cdot{ }^{\circ} \mathrm{C}\right)\right]$ & Tabulated mean value & \multicolumn{2}{|c|}{ EN 1745:2002, Table A.12 } \\
\hline
\end{tabular}

not request for a modification in known construction manufacturing processes. Plasterboard with microencapsulated PCMs is one of the most widespread solutions of PCM incorporation into building materials [13-16].

\section{PCM Plastering Mortar}

3.1. Test Methods and Requirements. The main goal of this section is to evaluate the feasibility of a new composite material, with inclusion of microencapsulated paraffin in cement based mortars, to be used in interior coatings for buildings. In order to be marketed within the European Union (EU) plastering mortars should respond to European Norm EN 998-1 [5]. Therefore, the development of a plastering mortar should comply with characteristics presented in Table 1 where test parameters and target properties for mortars are identified. In the scope of this work, apart from performing tests on the properties mentioned in Table 1 while developing a PCM-based mortar, complementary properties like enthalpy and specific heat were also evaluated.

3.2. Components and Formulation. The achieved mixture (used later on for further characterization) resulted from a set of preliminary analyses performed with the goal of evaluating the technical viability of the incorporation of microencapsulated PCM (industrially manufactured) into cement/lime based plastering mortar. Due to initial problems associated with the high cracking proneness of mortars containing PCM, the mixture composition was adjusted by an iterative process of trial and error, until the samples of the hardened mortar presented no visible cracking after the first hours of drying in controlled environment (with a temperature of $22 \pm 2^{\circ} \mathrm{C}$ and a relative humidity of $50 \% \pm 5 \%$ ). The trial samples, with $10 \mathrm{~cm} \times 10 \mathrm{~cm} \times 1 \mathrm{~cm}$, resulted from spreading of the fresh mortar over a brick surface. Besides all conventional components used in common plastering mortars,cement, lime, sand, and/or industrial fillers, and different kinds of additions (resins, fibers, cellulose deviants, and others) the trial mortars involved the use of PCM. The following text provides further information on the several constituents mentioned above, encompassing their main characteristics. The cement used is a type I class 42,5R according to NP-EN 197-1 [6]. The industrial aggregate used was calcium carbonate with $0.5-1.5 \mathrm{~mm}$ granulometric distribution. Resins (polymer ethyl-vinyl acetate, VAE) were applied in some of the trial formulations, with the primary function of improving adherence to the substrate (brick or concrete substrate) on low cement concentrations. However, they are known to reduce the blend's elasticity. The added fibers - polyacrylonitrile (PAN) $6 \mathrm{~mm}$ fibers - and aluminium powder are meant to compensate and redistribute the internal tension in the mortar, thus turning the shrinkage crack formation invisible. Cellulose deviants (cellulose ether) are used for high consistency development, as they impart good workability and enhance water retention considerably [17]. A microencapsulated paraffin powder (based on polymethyl methacrylate, highly cross-linked paraffin mixture), with commercial designation of "Micronal DS5008x," is used as PCM, with $23^{\circ} \mathrm{C}$ of melting point, an enthalpy of $100-$ $110 \mathrm{~kJ} / \mathrm{kg}$, and $300 \mathrm{~kg} / \mathrm{m}^{3}$ density, approximately [18].

After a trial-and-error procedure that consisted in casting several test specimens (formulations A to L shown in Table 2 , together with the corresponding compositions), adequate behaviour (i.e., absence of drying cracks) was obtained with formulations $\mathrm{J}, \mathrm{K}$, and $\mathrm{L}$. The formulation of a reference mortar, named as REFM, is also shown in Table 2, to better illustrate the similitude between formulation $\mathrm{L}$ and the formulation of a common plastering, which is commercially available for interior coating.

\subsection{Characterization and Classification: Thermal Properties.} The characterization of the developed plastering mortar had two main goals: the compliance with normative required values and consequent classification of the PCM mortar and the identification of the thermal complementary properties given by the presence of the PCM (like enthalpy and specific heat). The hardened mortars of the selected formulation $\mathrm{L}$, now renamed as PCMM (PCM mortar), were submitted to a set of characterization tests required by European Norm EN 998-1 [5]. The measured properties for PCMM are summarized in Table 3, where the corresponding test method/normalization is shown (the normalizations required for the developed tests are EN 1015 [19] and EN 1745 [20]). In regard to the properties shown in Table 3, it should be remarked that the water vapor permeability coefficient and the specific heat were estimated from the values presented in Table A.12 of EN 1745:2002 [20], as a function of the measured density of the composite mortar $\left(1170 \mathrm{~kg} / \mathrm{m}^{3}\right)$.

A heat flow meter apparatus was used to determine thermal conductivity of the new composite material according to ISO8301:1991 [21]. The thermal conductivity measured 
TABLE 2: Mix proportions of formulations A to L and REFM and surface appearance of samples A to L.

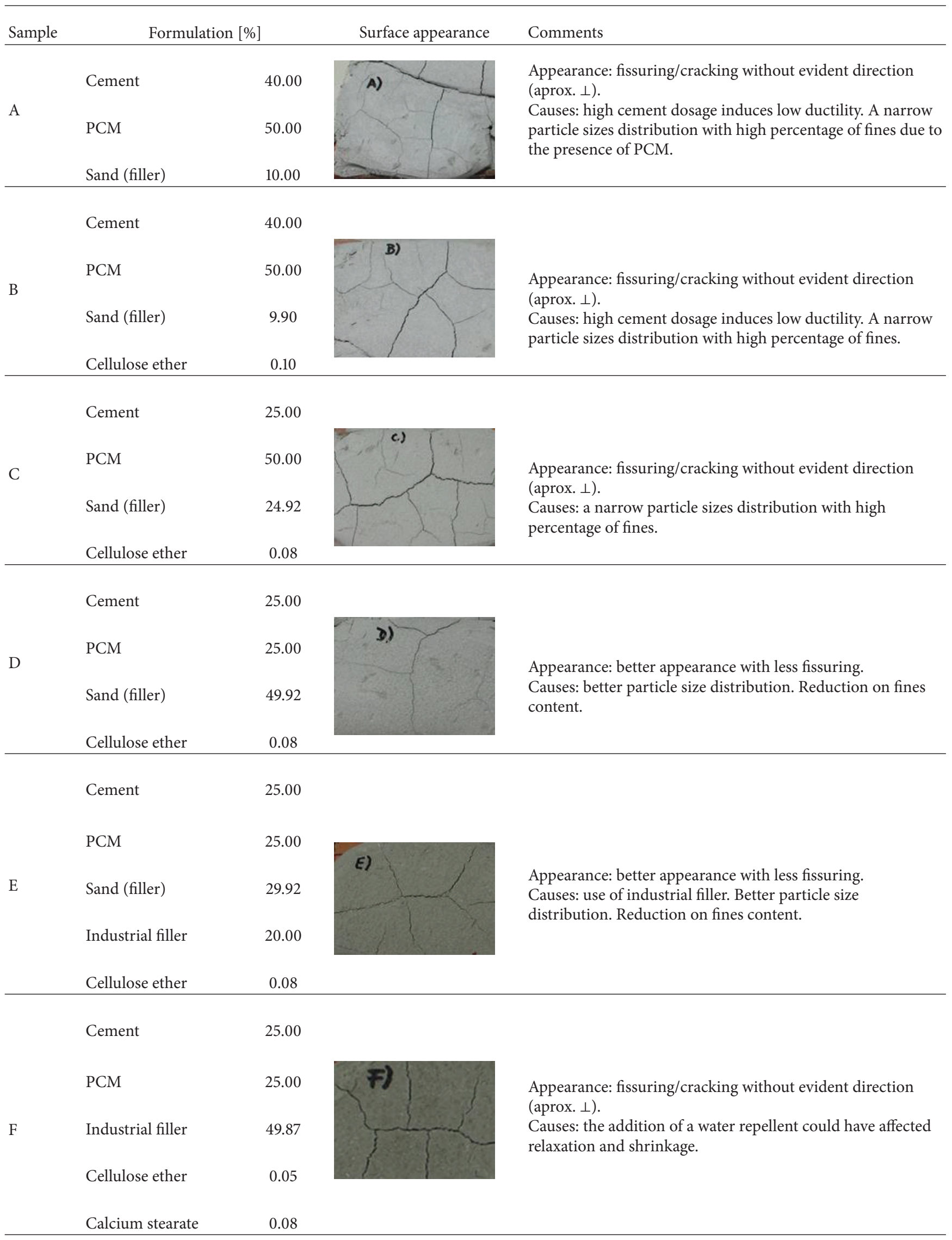


TABle 2: Continued.

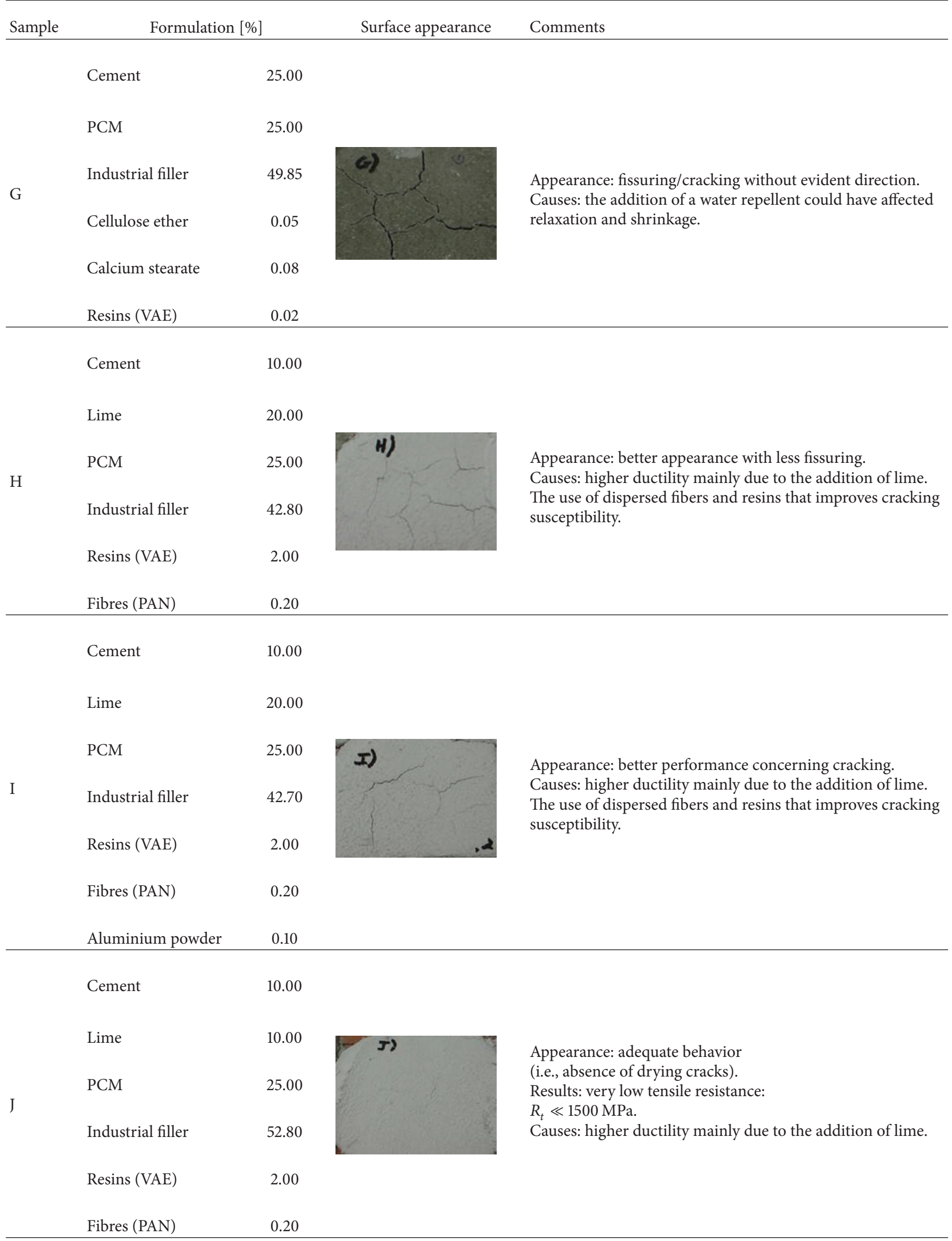


TABLe 2: Continued.

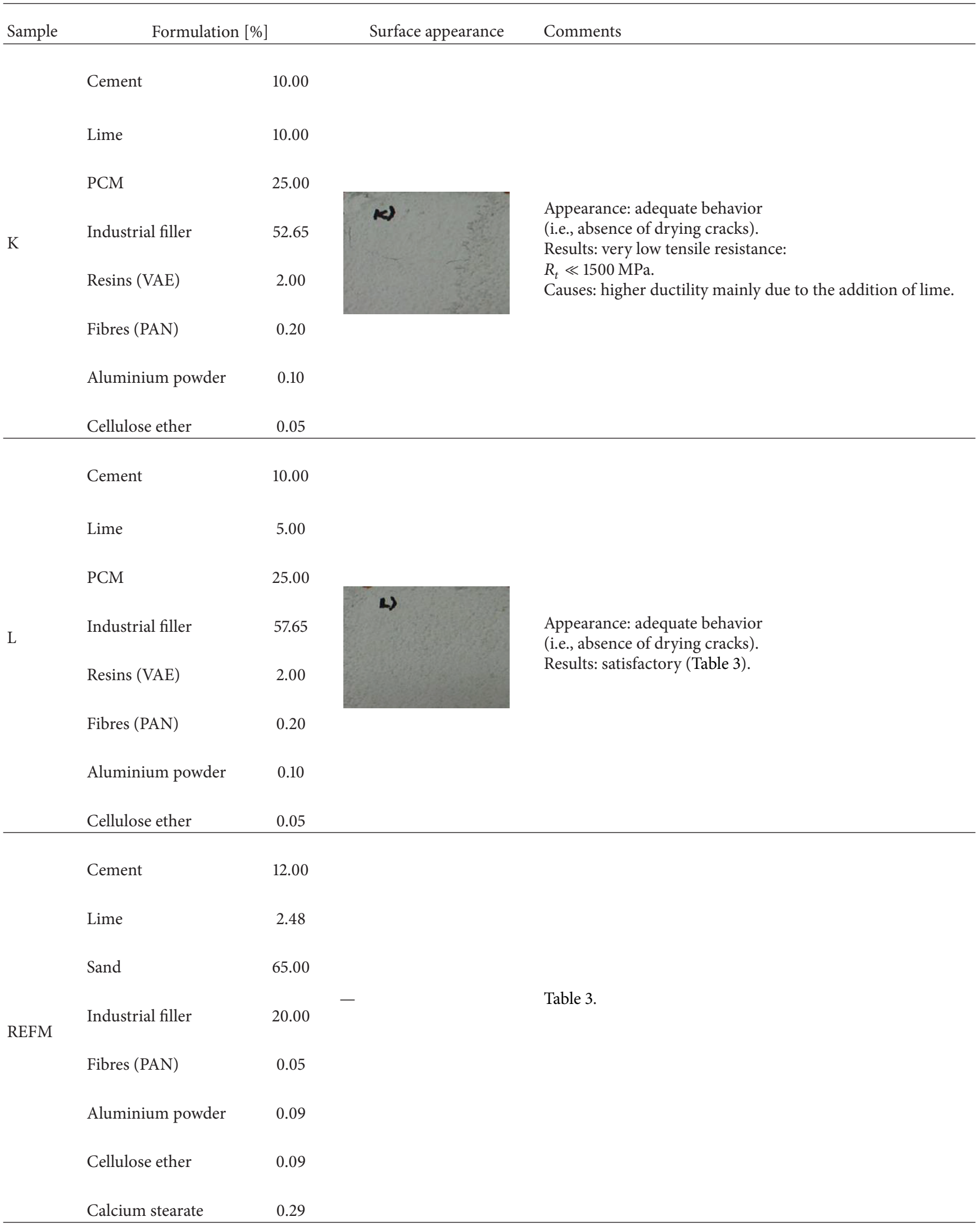

EN 998-1 [5]. 
TABLE 3: Results of the test performed to the composite mortar with formulation L (PCMM) and comparison to reference mortars (REFM).

\begin{tabular}{|c|c|c|c|}
\hline \multirow{2}{*}{ Test parameter } & \multicolumn{2}{|c|}{ Results } & \multirow{2}{*}{ Classification of PCMM/comments } \\
\hline & PCMM (LW) & REFM (GP) & \\
\hline Dry bulk density $\left[\mathrm{kg} / \mathrm{m}^{3}\right]$ & 1170 & 1400 & $\begin{array}{l}\text { LW/declared range of values: } \\
\rho \leq 1300 \mathrm{~kg} / \mathrm{m}^{3} .\end{array}$ \\
\hline Compressive strength $\left[\mathrm{N} / \mathrm{mm}^{2}\right]$ & 2.40 & 2.25 & CS I/similar behaviour. \\
\hline $\begin{array}{l}\text { Adhesion }\left[\mathrm{N} / \mathrm{mm}^{2}\right] \text { and fracture pattern FP (A, } \\
\mathrm{B}, \text { or } \mathrm{C})\end{array}$ & 0.35 FP: B & $0.30 \mathrm{FP}: \mathrm{B}$ & Similar behaviour. \\
\hline $\begin{array}{l}\text { Capillary water absorption (intended use in } \\
\text { external elements) }\end{array}$ & 4.89 & $\leq 4.0$ & W0/similar behaviour. \\
\hline $\begin{array}{l}\text { Water vapour permeability coefficient }(\mu) \\
\text { (intended use in external elements) }\end{array}$ & $5-10$ & $<15$ & EN 1745 [6], Table A.12. \\
\hline Thermal conductivity $\left[\mathrm{W} /\left(\mathrm{m} \cdot{ }^{\circ} \mathrm{C}\right)\right]$ & 0.29 & 0.61 & $\begin{array}{l}\text { Similar behaviour when compared } \\
\text { to LW mortars. }\end{array}$ \\
\hline Latent heat $[\mathrm{kJ} / \mathrm{kg}]$ & $\approx 25$ & - & - \\
\hline Melting temperature $\left[{ }^{\circ} \mathrm{C}\right]$ & $\approx 23$ & - & - \\
\hline Melting temperature range $\left[{ }^{\circ} \mathrm{C}\right](90 \%)$ & $23-25$ & - & - \\
\hline Specific heat (solid) $\left[\mathrm{kJ} /\left(\mathrm{kg} \cdot{ }^{\circ} \mathrm{C}\right)\right]$ & 1.0 & 1.0 & EN 1745 [6], Table A.12. \\
\hline
\end{tabular}

with this experimental technique was $0.295 \mathrm{~W} / \mathrm{m} \mathrm{K}$. Also, the melting temperature and the fusion enthalpy were experimentally determined through differential scanning calorimetry (DSC) tests with recourse to a Diamond DSC from Perkin Elmer. A sample of the supplied PCM mortar (powder) of approximately $7.7 \mathrm{mg}$ was tested and an enthalpy of $22.6 \mathrm{~kJ} / \mathrm{kg}$ was registered. This result came close to what would be expected $(25 \mathrm{~kJ} / \mathrm{kg})$, assuming that the enthalpy is linearly proportional to the fraction of paraffin amount in the sample (25\%), bearing in mind that the PCM is the only material in the mixture to experiment phase transition (from solid to liquid) in the range of studied temperatures $\left(5-50^{\circ} \mathrm{C}\right)$. From these results it may be concluded that the PCM keeps its characteristics when integrated into hardened cement based mortars. Therefore, from now on, it will be considered that the composite mortar containing $25 \%$ of PCM has a melting point of $23^{\circ} \mathrm{C}$ and a melting enthalpy of $25 \mathrm{~kJ} / \mathrm{kg}$ in a $2^{\circ} \mathrm{C}$ temperature range.

The comparison of characteristics between PCMM and REFM is presented in Table 3. These results confirm the expected similarity in behaviour for the developed plastering mortar in view of the PCM chemically inert characteristics, which was introduced in the mix by replacing aggregates.

\section{Numerical Simulation}

4.1. Field Equations: PCM Model with EnergyPlus. Traditionally EnergyPlus uses conduction transfer functions (CTF) to simulate surface constructions. These are linear equations, relatively simple, which allow the calculation of the conduction heat transfer through a completed layered building surface. However, with this method, it is impossible to include temperature dependent thermal properties, and thus modelling behaviours such as phase change enthalpy become unmanageable [22].

The inclusion of a new solution algorithm that utilizes an implicit finite difference procedure (CondFD) upgraded
EnergyPlus to simulate the effect of PCM. This new model was tested and validated against multiple test suites $[3,4]$. The CondFD algorithm in EnergyPlus uses an implicit finite difference scheme coupled with an enthalpy-temperature function. This function is the users' input to accurately account for energy transfer during phase change. EnergyPlus includes two different options for the specific scheme or formulation used for the finite difference model. Before version 7, EnergyPlus used Crank-Nicholson solution scheme and then a new algorithm was added and is referred to as fully implicit. Both algorithms are based on an Adams-Moulton solution approach but the fully implicit one is considered of first order in time (Crank-Nicholson solution scheme is considered of second order). The model equation for the fully implicit scheme is described in [23]

$$
\begin{aligned}
C_{p} \cdot \rho & \cdot \Delta x \cdot \frac{T_{i}^{j+1}-T_{i}^{j}}{\Delta t} \\
& =\left(k_{w} \cdot \frac{T_{i+1}^{j+1}-T_{i}^{j+1}}{\Delta x}+k_{E} \cdot \frac{T_{i-1}^{j+1}-T_{i}^{j+1}}{\Delta x}\right),
\end{aligned}
$$

where $T$ is the node temperature; $i$ is the node being modelled; $i+1$ is the adjacent node to interior of construction; $i-1$ is the adjacent node to exterior of construction; $j+1$ is the new time step; $j$ is the previous time step; $\Delta t$ is the calculation time step; $\Delta x$ is the finite difference layer thickness (always less than construction layer thickness); $C_{p}$ is the specific heat of material; $k_{w}$ is the thermal conductivity for interface between $i$ node and $i+1$ node; $k_{E}$ is the thermal conductivity for interface between $i$ node and $i-1$ node; and $\rho$ is the density of material.

This equation is complemented by (2) that relates enthalpy and temperature and is used to develop an equivalent specific heat at each time step:

$$
h_{i}=\operatorname{HTF}\left(T_{i}\right) \text {, }
$$




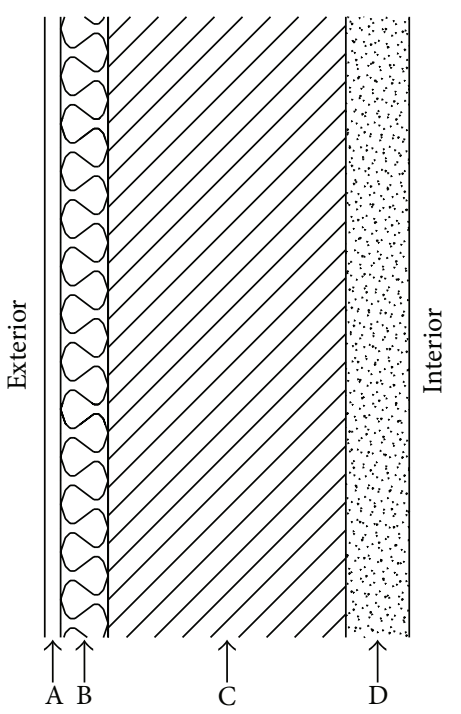

FIGURE 2: Wall configuration.

where HTF is an enthalpy-temperature function that uses data from user input.

The algorithm also permits including a temperature dependent thermal conductivity:

$$
k=k_{0}+k_{1}\left(T_{i}-20\right),
$$

where $k_{0}$ is the $20^{\circ} \mathrm{C}$ thermal conductivity value and $k_{1}$ is the change in conductivity per degree temperature difference from $20^{\circ} \mathrm{C}$.

4.2. Geometry Model and Parameters. In this research the effect of introducing PCM in a plastering mortar on the external walls of a simple office cell located in Portugal is explored. A sensitivity analysis was performed, which included the study of the influence of material properties variation, such as melting temperature ranges and enthalpy, and the study of the influence of installing the office cell in different climatic regions. Discomfort due to overheating and cooling energy demand were the outputs used in the analysis.

The geometry adopted was an office cell like the one of ASHRAE Standard 140_Bestest Case 900 [24] as well as the internal gains and ventilation. The introduction of PCM on a plastering mortar in the building envelope (PCMM) and the use of a reference mortar (REFM) were compared. Figure 2 shows the main configuration used to model the walls and Table 4 provides the thermal conductivity, density, specific heat, and thickness of each layer.

Simulations were performed in two cities of Portugal, Lisbon and Porto, which represent different climatic regions. Both cities are located near the coast but, especially during summer, Lisbon is warmer than Porto. Figure 3 presents the monthly mean air temperature $\left(T_{\text {air }}\right)$, the sol-air temperature $\left(T_{\text {sol-air }}\right)$, and the total solar radiation (direct and diffuse) of Lisbon and Porto [23].

All the simulations were performed with software EnergyPlus, for the cooling season, between $01 / 04$ and 30/09, on an hourly basis and considering 60 time steps per hour.
TABLE 4: Material properties.

\begin{tabular}{lcccc}
\hline Element ID & $\begin{array}{c}\text { Conductivity } \\
{[\mathrm{W} /(\mathrm{m} \cdot \mathrm{K})]}\end{array}$ & $\begin{array}{c}\text { Density } \\
{\left[\mathrm{kg} / \mathrm{m}^{3}\right]}\end{array}$ & $\begin{array}{c}\text { Specific heat } \\
{[\mathrm{kJ} /(\mathrm{kg} \cdot \mathrm{K})]}\end{array}$ & $\begin{array}{c}\text { Thickness } \\
{[\mathrm{m}]}\end{array}$ \\
\hline (a) Render & 1.00 & 1800 & 1000 & 0.005 \\
(b) Insulation & 0.04 & 10 & 1400 & 0.04 \\
(c) Block & 0.51 & 1400 & 1000 & 0.10 \\
(d) Mortar & 0.30 & 1400 & 1000 & 0.03 \\
\hline
\end{tabular}

TABLE 5: "Free-floating" scenario.

\begin{tabular}{lccc}
\hline Case ID & $L[\mathrm{~kJ} / \mathrm{kg}]$ & $T_{1}\left[{ }^{\circ} \mathrm{C}\right]$ & $T_{2}\left[{ }^{\circ} \mathrm{C}\right]$ \\
\hline PCM23/25_25 & 25 & 23 & 25 \\
PCM23/25_100 & 100 & 23 & 25 \\
PCM23/25_200 & 200 & 23 & 25 \\
PCM24/26_25 & 25 & 24 & 26 \\
PCM24/26_100 & 100 & 24 & 26 \\
PCM24/26_200 & 200 & 24 & 26 \\
PCM25/27_25 & 25 & 25 & 27 \\
PCM25/27_100 & 100 & 25 & 27 \\
PCM25/27_200 & 200 & 25 & 27 \\
PCM26/28_25 & 25 & 26 & 28 \\
PCM26/28_100 & 100 & 26 & 28 \\
PCM26/28_200 & 200 & 26 & 28 \\
REFM & - & - & - \\
\hline
\end{tabular}

4.2.1. Discomfort Analysis due to Overheating. The first performed analysis was the evaluation of the discomfort due to overheating, assuming a "free-floating" scenario (without cooling system). The discomfort was assessed by computing the degree-hours. The degree-hours $\left(\mathrm{DH}_{25}\right)$ can be defined as the sum of the differences between air temperature and a reference value as follows:

$$
\mathrm{DH}_{25}=\sum_{i=1}^{n}\left(T_{i}-25\right) \wedge T_{i}>25
$$

where $T_{i}$ is the interior temperature.

It performed a sensitivity analysis that aimed to understand if overheating minimization can be achieved by the increasing of enthalpy amount in the mortar or by changing the PCM melting temperature range. A numerical simulation was carried out, which included 13 cases resulting from the combination of different phase change ranges (melting temperatures from $23 / 25^{\circ} \mathrm{C}$ to $26 / 28^{\circ} \mathrm{C}$ ) with varied enthalpy values of 25,100 , and $200 \mathrm{~kJ} / \mathrm{kg}$, as well as the reference case without PCM, as can be observed in Figure 4 and Table 5.

4.2.2. Analysis of the Effect of Introducing an HVAC System. In the second analysis, the effect of introducing an HVAC system in the office cell was evaluated by computing the energy demand for cooling assuming a temperature set point of $25^{\circ} \mathrm{C}$. For this sensitivity analysis only two melting temperature ranges were considered, resulting in 7 cases (Table 6).

4.3. Simulation Results. The comfort sensation is guaranteed by temperature level and stabilization inside a building space 


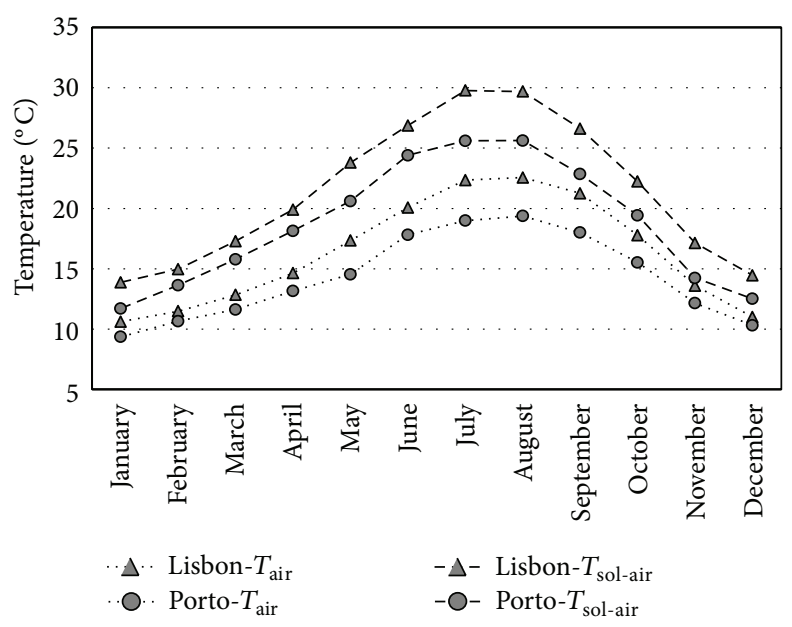

(a)

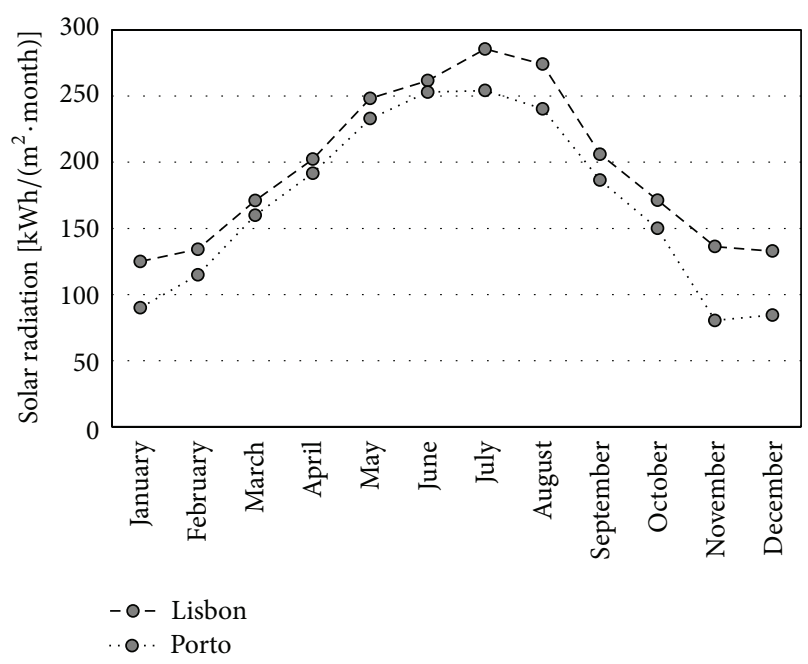

(b)

FIGURE 3: Monthly mean temperature.

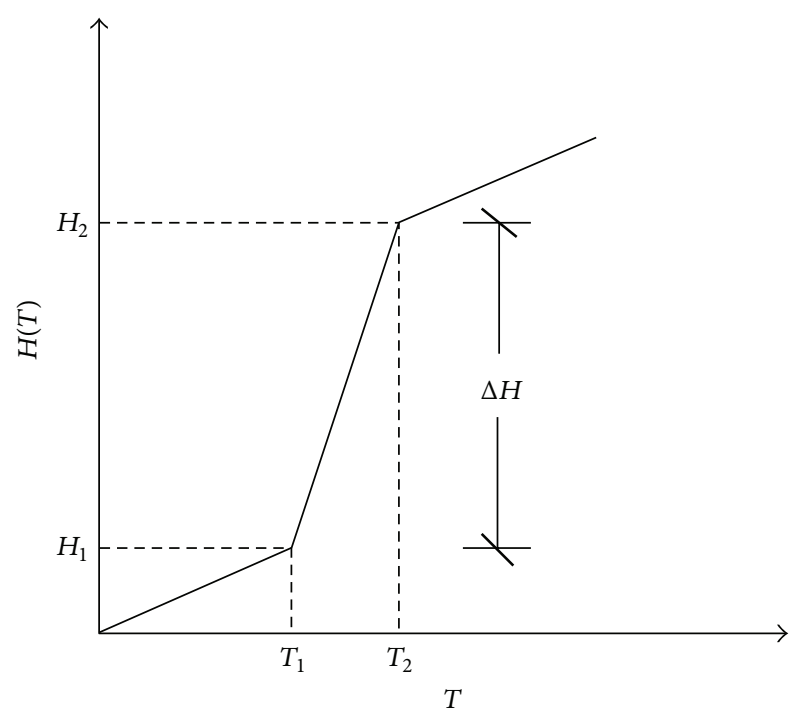

FIgURE 4: Enthalpy versus temperature.

TABLE 6: HVAC scenario.

\begin{tabular}{lccc}
\hline Case ID & $L[\mathrm{~kJ} / \mathrm{kg}]$ & $T_{1}\left[{ }^{\circ} \mathrm{C}\right]$ & $T_{2}\left[{ }^{\circ} \mathrm{C}\right]$ \\
\hline PCM23/25_25 & 25 & 23 & 25 \\
PCM23/25_100 & 100 & 23 & 25 \\
PCM23/25_200 & 200 & 23 & 25 \\
PCM24/26_25 & 25 & 24 & 26 \\
PCM24/26_100 & 100 & 24 & 26 \\
PCM24/26_200 & 200 & 24 & 26 \\
REFM & - & - & - \\
\hline
\end{tabular}

[25]. PCM contributes to interior temperature stabilization being an interesting solution to improve comfort conditions and to minimize energy consumption $[1,12,26]$.
4.3.1. Results for the Discomfort Analysis due to Overheating. The first approach of the sensitivity analysis was for the "freefloating" situation. Degree-hours for $25^{\circ} \mathrm{C}$ basis were used as the evaluation parameter to assess the discomfort due to overheating. As an example, Figure 5 shows the simulation result of a daily temperature profile in Lisbon for different scenarios: the effect of enthalpy variation is exposed in Figure 5(a), where the same melting temperature, of 24$26^{\circ} \mathrm{C}$, for three different enthalpies, was calculated, and in Figure 5(b), where the same enthalpy, of $200 \mathrm{~kJ} / \mathrm{kg}$, for four different melting temperature ranges, was studied.

Attending to the results shown in Figure 5(a) the peak temperature for the reference case REFM was $30.4^{\circ} \mathrm{C}$, dropping to $28.7^{\circ} \mathrm{C}$ when considering a PCMM with $24-26^{\circ} \mathrm{C}$ and an enthalpy of $200 \mathrm{~kJ} / \mathrm{kg}$ (PCM24/26_200). With this plastering mortar, PCM24/26_200, the interior temperature of the office cell varied between 24.5 and $28.7^{\circ} \mathrm{C}$, reaching a temperature interval of $\Delta T_{\text {PCM24/26_200 }}=3.3^{\circ} \mathrm{C}$ inside the building. On the other hand, with the REFM (without PCM), an interval of $\Delta T_{\text {REFM }}=5.3^{\circ} \mathrm{C}$, between 25.1 and $30.4^{\circ} \mathrm{C}$, was achieved. The presence of the PCM was observed lowering the interior temperature peak, reducing the temperature variation within the building, and increasing the period of time during which the temperature is maintained within the melting range near $25^{\circ} \mathrm{C}$ (i.e., comfort temperatures).

Regarding Figure 5(b) the most interesting performance was obtained with PCM25/27_200 and PCM24/26_200 with a temperature variation between 24.7 and $28.4^{\circ} \mathrm{C}$, with $\Delta T_{\text {PCM25/27_200 }}=3.7^{\circ} \mathrm{C}$, and 24.5 and $28.7^{\circ} \mathrm{C}$, with $\Delta T_{\text {PCM24/26_200 }}=4.2^{\circ} \mathrm{C}$, respectively. However, it is important to underline that all the simulated scenarios correspond to an improvement when compared to the reference case without PCM (REFM). It is clear that PCM incorporated in plastering mortars changed the interior temperature profile, helping to stabilize them and dropping temperature peaks.

The "overheating improvement" was evaluated by a percentage resulting from the difference of degree-hours $\mathrm{DH}_{25}$ 


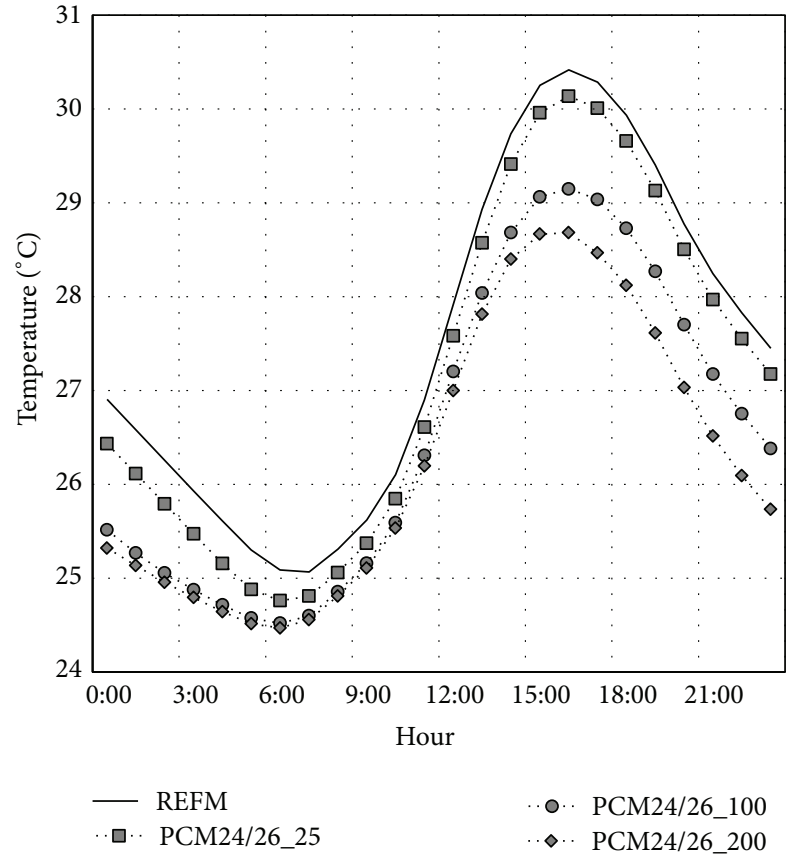

(a)

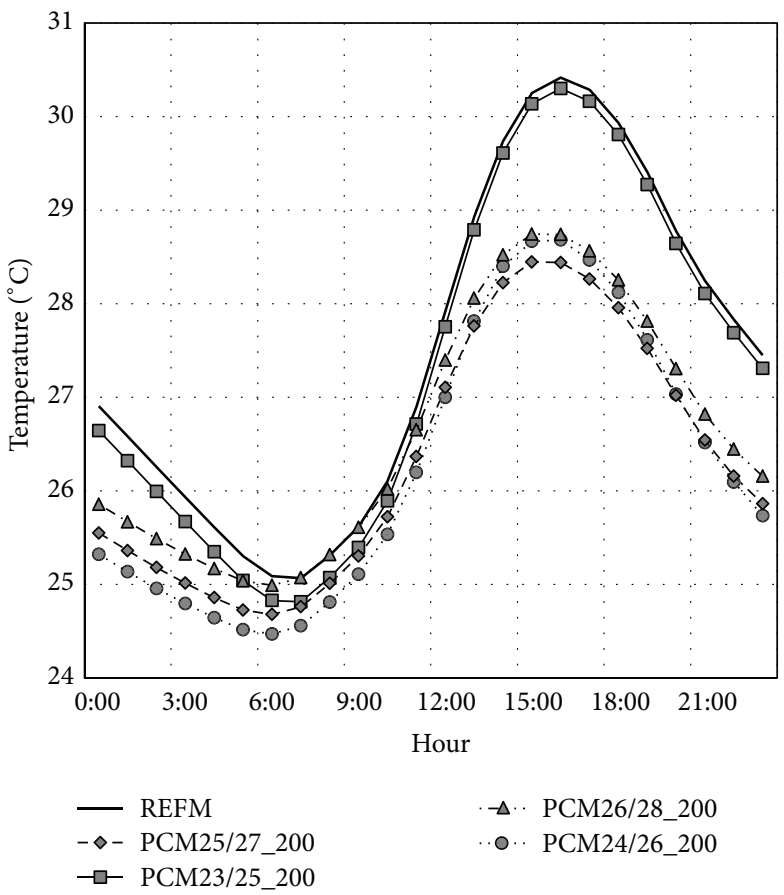

(b)

Figure 5: Assessed interior temperatures for the office cell located in Lisbon: (a) enthalpy effect, (b) melting temperature effect.

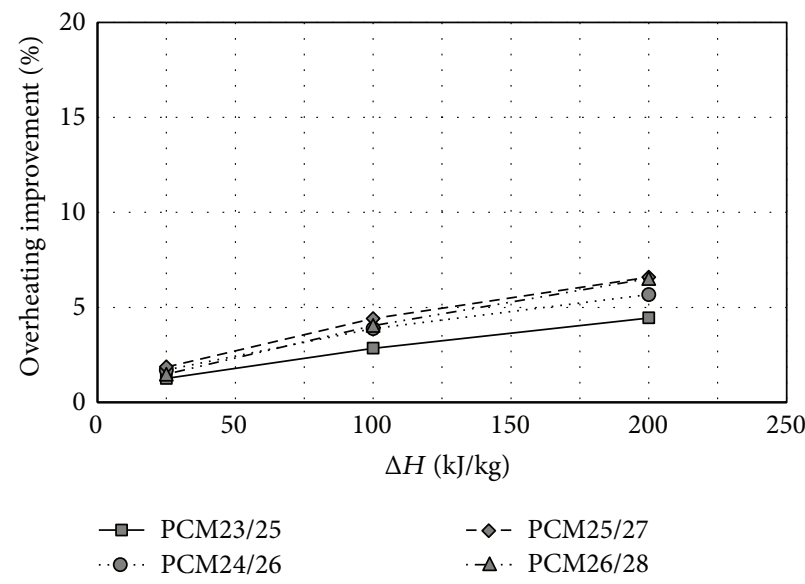

(a)

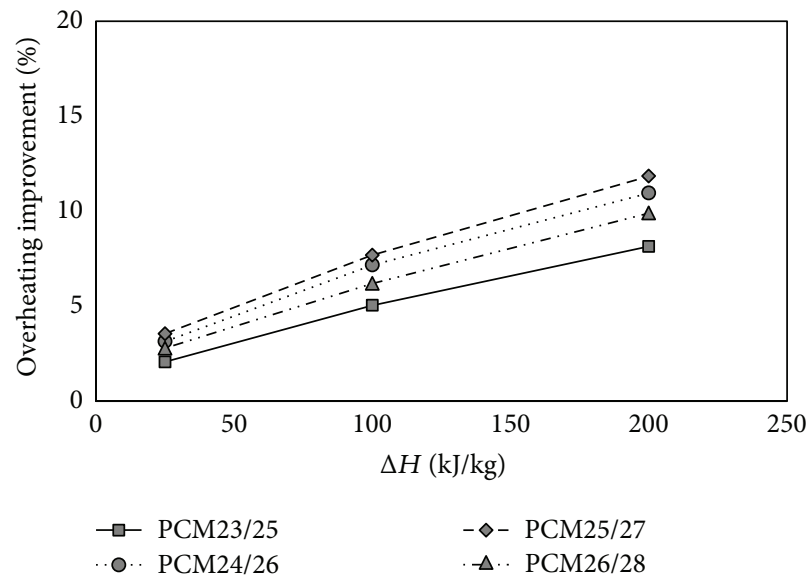

(b)

FIGURE 6: Discomfort analysis due to overheating inside an office cell placed in (a) Lisbon and (b) Porto.

between the use of REFM as plastering in the office cell and the use of different PCMM. Attending to the analysis for "free-floating" situation, with a $25^{\circ} \mathrm{C}$ basis for $\mathrm{DH}$ to assess the discomfort due to overheating, with results plotted in Figure 6, maximum overheating improvement was $12 \%$, obtained for the office cell placed in Porto with PCM25/27_200. The lowest value was registered for the office cell placed in Lisbon for PCM23/25_25 (a PCM with an enthalpy of $25 \mathrm{~kJ} / \mathrm{kg}$ and a fusion temperature range between 23 and $25^{\circ} \mathrm{C}$ ). Still, the overheating improvement was $2 \%$.

These results are in line with other authors $[1,12,26,27]$. Some additional improvement would be expected if some changes were made in the building envelope and ventilation. Indeed, the model used in this analysis is very exposed to overheating problems, due to a combination of large solar heat gains (no adequate solar shading device is used), lack of insulation in the roof, and poor ventilation rates especially during the night (no night ventilation procedure is established). This situation leads to very high interior temperatures (situations with interior temperatures over $30^{\circ} \mathrm{C}$ were regularly observed) and, therefore, there is a large untapped potential in the PCM. The lower overheating improvements obtained in Lisbon are also explained by this situation since the exterior climate conditions are more aggressive than in 


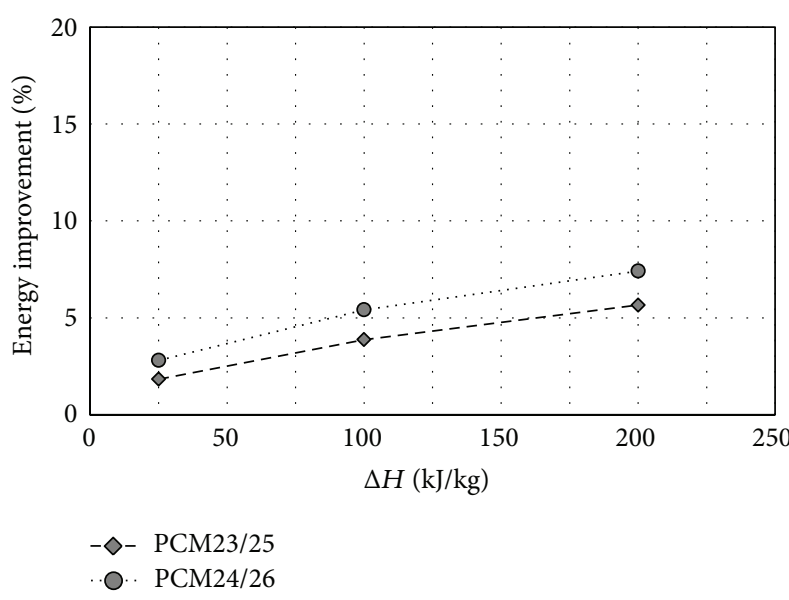

(a)

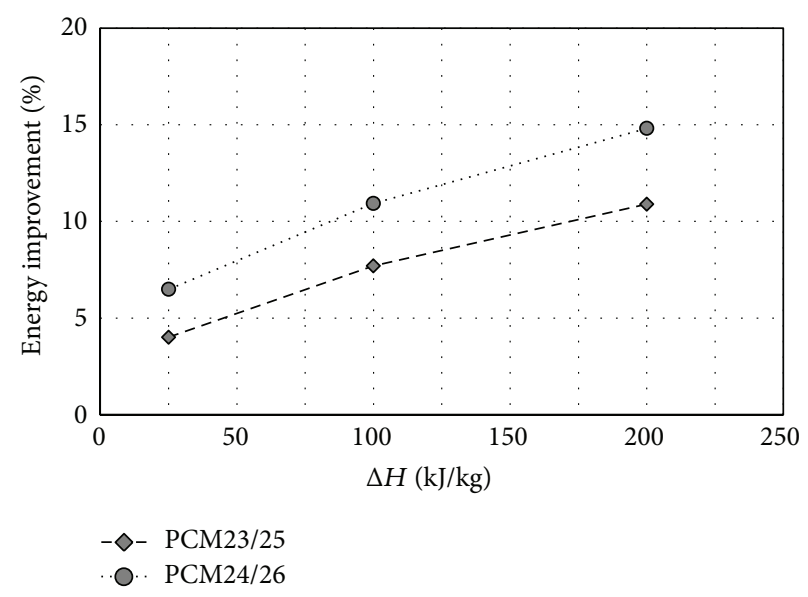

(b)

Figure 7: Energy savings analysis of the inside of an office cell placed in (a) Lisbon and (b) Porto.

Porto (higher temperatures and more intense solar radiation).

4.3.2. Results for the Effect Analysis of Introducing an HVAC System. A similar analysis can be made for the improvement in the cooling energy demand when using PCM in the office cell with an HVAC system. The "energy savings" are evaluated by a percentage resulting from the difference in the annual cooling energy demand between the use of REFM as plastering in the office cell and the use of different PCMM. Attending to the results, shown in Figure 7, plastering mortar PCM24/26_200 used in an office cell placed at Porto can reduce cooling energy demand by $15 \%$. The same solution for the climatic conditions set for Lisbon resulted in $8 \%$ of energy savings.

On the analysis of the effect of introducing an HVAC system, the PCM presence was observed lowering the cooling energy demand necessary to maintain the temperatures inside the office cell close to the comfort temperature, $25^{\circ} \mathrm{C}$.

Both sensitivity analyses produced very encouraging results that sustain future works on this research in order to optimize the use of PCM, adapting enthalpy and melting temperature ranges to climatic conditions and building's envelope.

\section{Conclusions and Future Works}

The main conclusions of this study are as follows.

(i) PCM can be incorporated into mortars without compromising the properties that are desirable for their application as plastering materials.

(ii) The potential of advanced simulation tools to evaluate and optimize the usage of PCM materials in the indoor temperature control, allowing for an improvement in the comfort conditions and/or in the cooling energy demand, was explored in this paper.

(iii) A sensitivity analysis regarding the enthalpy and melting temperature effect was performed and the temperature stabilization potential of the plastering PCM has been demonstrated. It was found that changes in the enthalpy value can produce a higher impact than varying the melting temperature of the PCM.

(iv) Considering a "free-floating" space, the inclusion of a plastering mortar containing PCM with an enthalpy of $200 \mathrm{~kJ} / \mathrm{kg}$ and a fusion temperature range between 25 and $27^{\circ} \mathrm{C}$ can improve the comfort conditions by $12 \%$. For the office with an HVAC system, the inclusion of a plastering mortar containing PCM with an enthalpy of $200 \mathrm{~kJ} / \mathrm{kg}$ and a fusion temperature range between 24 and $26^{\circ} \mathrm{C}$ can improve the cooling energy demand by $15 \%$.

\section{Conflict of Interests}

The authors declare that there is no conflict of interests regarding the publication of this paper.

\section{References}

[1] P. Ahadi, "Applications of nanomaterials in construction with an approach to energy issue," Advanced Materials Research, vol. 261-263, pp. 509-514, 2011.

[2] A. V. Sá, M. Azenha, H. de Sousa, and A. Samagaio, “Thermal enhancement of plastering mortars with Phase Change Materials: experimental and numerical approach," Energy and Buildings, vol. 49, pp. 16-27, 2012.

[3] P. C. Tabares-Velasco and B. Griffith, "Diagnostic test cases for verifying surface heat transfer algorithms and boundary conditions in building energy simulation programs," Journal of Building Performance Simulation, vol. 5, pp. 329-346, 2011.

[4] P. C. Tabares-Velasco, C. Christensen, and M. Bianchi, "Verification and validation of EnergyPlus phase change material model for opaque wall assemblies," Building and Environment, vol. 54, pp. 186-196, 2012. 
[5] CEN, "EN 998-1: specification for mortar masonry. Part 1: rendering and plastering mortar," CEN, (European Commitee for Stardardization), Brussels, Belgium, 2013.

[6] CEN, "EN 197-1: cement. Part 1: composition, specifications and conformity criteria for common cements," CEN, (European Commitee for Stardardization), Brussels, Belgium, 2001.

[7] J. Dieckmann, "Latent heat storage in concrete," 2008, http:// www.eurosolar.org/new/pdfs_neu/Thermal/IRES2006_Dieckmann.pdf.

[8] D. W. Hawes, D. Feldman, and D. Banu, "Latent heat storage in building materials," Energy and Buildings, vol. 20, no. 1, pp. 7786, 1993.

[9] D. Zhou, C. Y. Zhao, and Y. Tian, "Review on thermal energy storage with phase change materials (PCMs) in building applications," Applied Energy, vol. 92, pp. 593-605, 2012.

[10] M. Koschenz and B. Lehmann, "Development of a thermally activated ceiling panel with PCM for application in lightweight and retrofitted buildings," Energy and Buildings, vol. 36, no. 6, pp. 567-578, 2004.

[11] K. Lin, Y. Zhang, X. Xu, H. Di, R. Yang, and P. Qin, "Experimental study of under-floor electric heating system with shapestabilized PCM plates," Energy and Buildings, vol. 37, no. 3, pp. 215-220, 2005.

[12] L. F. Cabeza, C. Castellón, M. Nogués, M. Medrano, R. Leppers, and O. Zubillaga, "Use of microencapsulated PCM in concrete walls for energy savings," Energy and Buildings, vol. 39, no. 2, pp. 113-119, 2007.

[13] D. Feldman, D. Banu, and D. W. Hawes, "Development and application of organic phase change mixtures in thermal storage gypsum wallboard," Solar Energy Materials and Solar Cells, vol. 36, no. 2, pp. 147-157, 1995.

[14] F. Kuznik, J. Virgone, and J.-J. Roux, "Energetic efficiency of room wall containing PCM wallboard: a full-scale experimental investigation," Energy and Buildings, vol. 40, no. 2, pp. 148-156, 2008.

[15] C.-M. Lai, R. H. Chen, and C.-Y. Lin, "Heat transfer and thermal storage behaviour of gypsum boards incorporating microencapsulated PCM," Energy and Buildings, vol. 42, no. 8, pp. 1259-1266, 2010.

[16] C. Hasse, M. Grenet, A. Bontemps, R. Dendievel, and H. Sallée, "Realization, test and modelling of honeycomb wallboards containing a Phase Change Material," Energy and Buildings, vol. 43, no. 1, pp. 232-238, 2011.

[17] A. K. Athienitis, C. Liu, D. Hawes, D. Banu, and D. Feldman, "Investigation of the thermal performance of a passive solar test-room with wall latent heat storage," Building and Environment, vol. 32, no. 5, pp. 405-410, 1997.

[18] BASF, BASF The Chemical Company, GmbH. Phase Change Material. Micronal PCM, 2010, http://www.micronal.de/portal/ basf/ien/dt.jsp?setCursor=1_290798.

[19] CEN, "EN, 1015: methods of test for mortar for masonry," vol. EN1015, CEN, (European Commitee for Stardardization), Brussels, Belgium, 2006.

[20] CEN, "EN, 1745: masonry and masonry products. Methods for determining design thermal values," CEN, (European Commitee for Stardardization), Brussels, Belgium, 2002.

[21] ISO, "ISO, 8301: thermal insulation: determination of steadystate thermal resistance and related properties. Heat flow meter apparatus," ISO, (International Organization for Standardization), Geneve, Switzerland, 1991.
[22] C. O. Pedersen, "Advanced zone simulation in EnergyPlus: incorporation of variable properties and phase change material (PCM) capability," Building Simulation 2007, Beijing, China, 2007.

[23] EnergyPlus, EnergyPlus Engineering Reference: The Reference to EnergyPlus Calculations: Ernest Orlando Lawrence Berkeley National Laboratory, 2012.

[24] ASHRAE, "ASHRAE Standard 140-2007: Standard Method of Test for the Evaluation of Building Energy Analysis Computer Programs," Atlanta, Ga, USA, 2007.

[25] ISO, "ISO, 7730: ergonomics of the thermal environment. Analytical determination and interpretationof thermal comfort using calculation of the PMV and PPD indices and local thermal comfort criteria," ISO, (International Organization for Standardization), Geneve, Switzerland, 2005.

[26] A. Castell, I. Martorell, M. Medrano, G. Pérez, and L. F. Cabeza, "Experimental study of using PCM in brick constructive solutions for passive cooling," Energy and Buildings, vol. 42, no. 4, pp. 534-540, 2010.

[27] N. Soares, J. J. Costa, A. R. Gaspar, and P. Santos, "Review of passive PCM latent heat thermal energy storage systems towards buildings'energy efficiency," Energy and Buildings, vol. 59, pp. 82-103, 2013. 

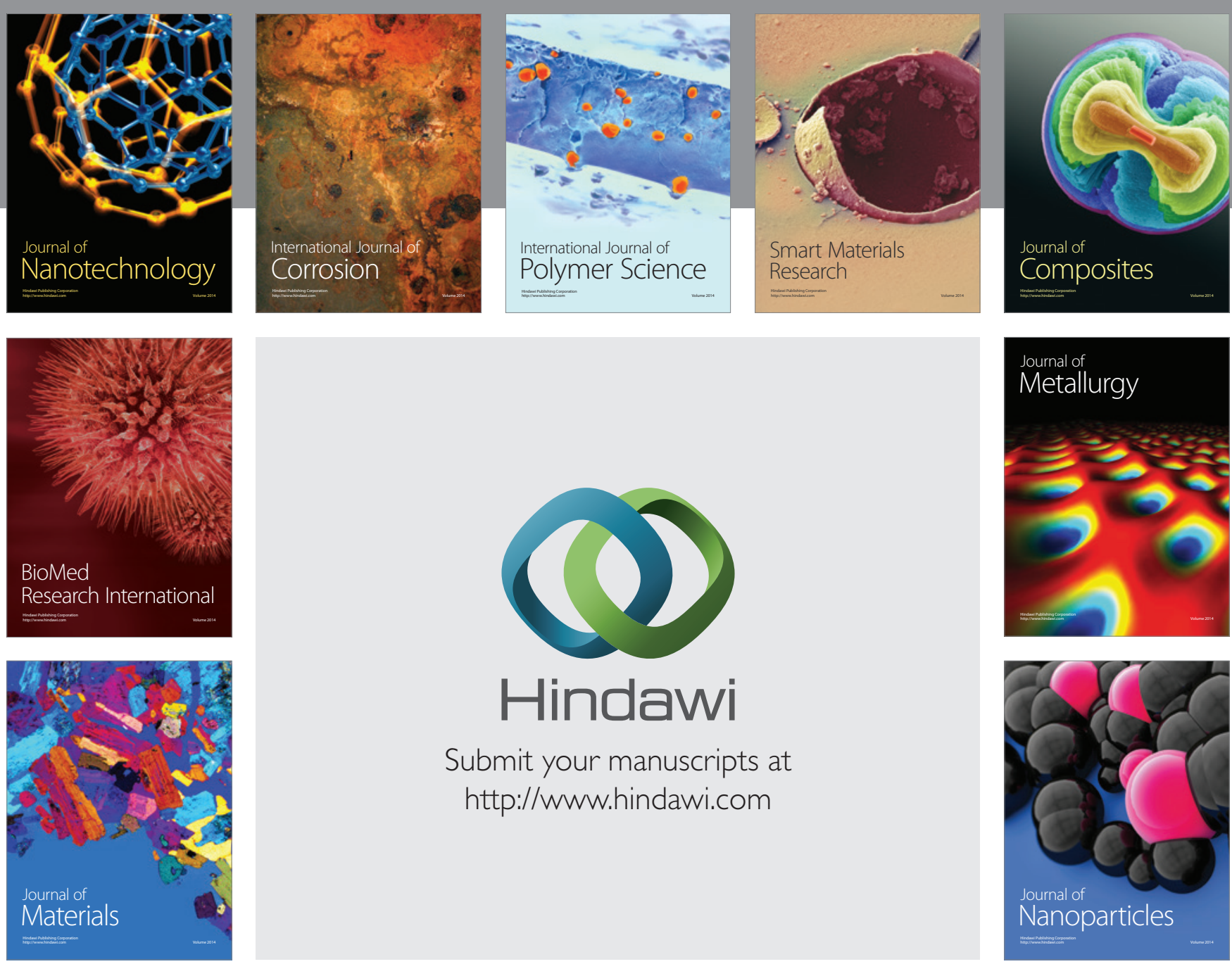

Submit your manuscripts at http://www.hindawi.com
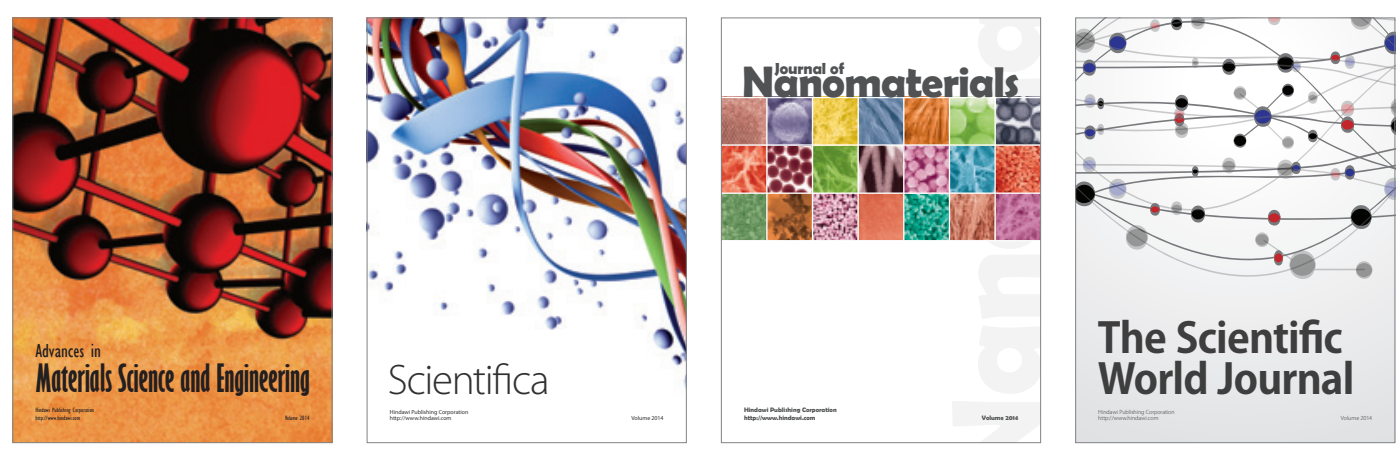

\section{The Scientific World Journal}
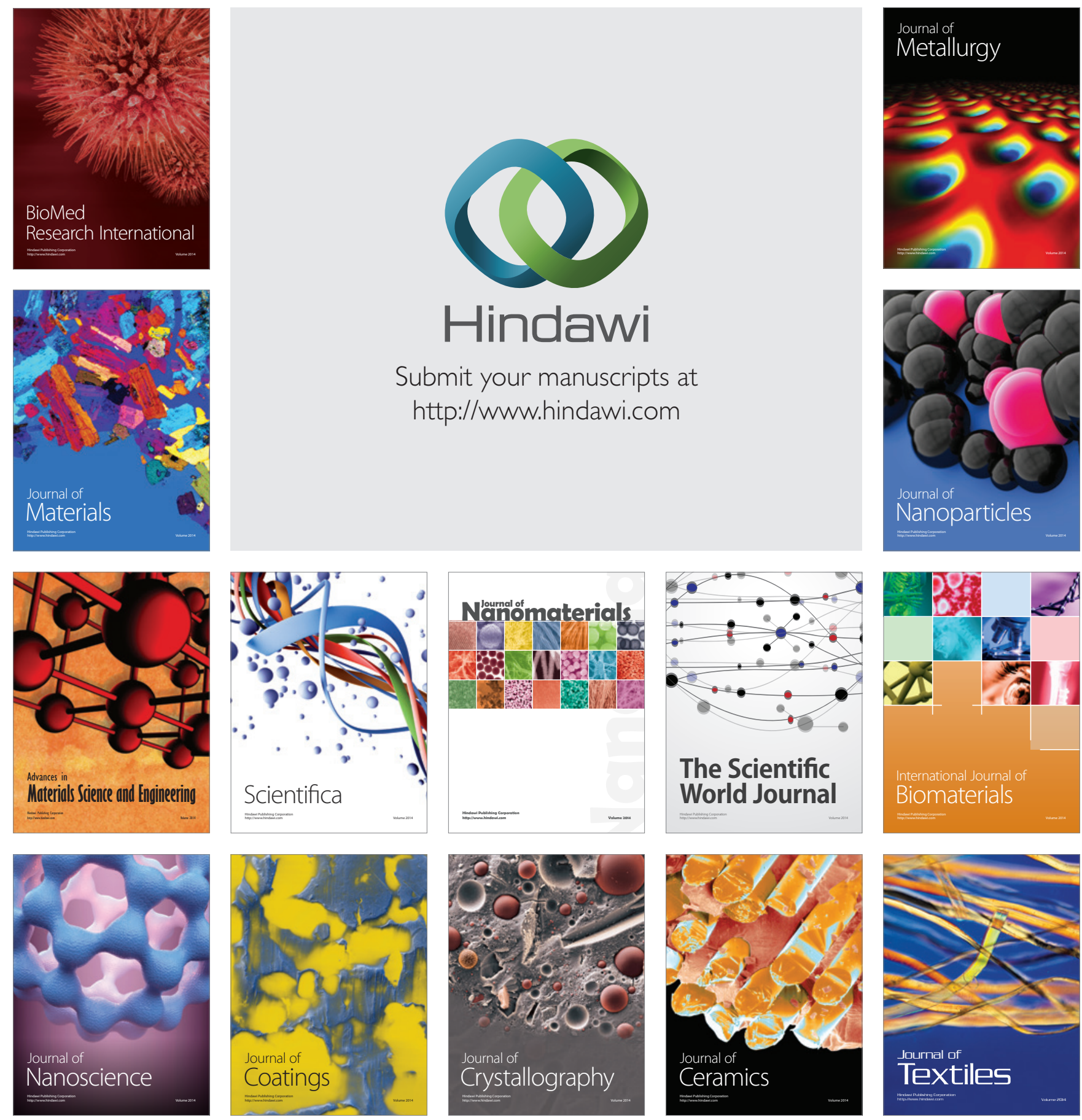